Bangladesh Journal of Anatomy January 2009, Vol. 7 No. 1 pp. 55-61

\title{
Views of Teachers Regarding Course Contents of Anatomy in Post Graduate MD Internal Medicine Curriculum
}

\author{
Laila Anjuman Banu ${ }^{1}$, M Shomsher Ali ${ }^{2}$
}

\begin{abstract}
Context: Anatomy is a compulsory subject for postgraduate medical courses of Bangladesh. MD internal medicine is a clinical course run by different universities of Bangladesh.

To maintain a standard of medical education a curriculum is essential for a course. Again course content is an essential part of a curriculum. Doctor of Medicine (MD) courses consist of three parts. In Part-I, students study the basic medical subjects for six months. To produce clinicians with appropriate anatomical knowledge in a short time within six months period proper customized (relevant) course content regarding Anatomy part is necessary.

But the problem is that in our postgraduate course much subjectivity is present in every aspects of curriculum. This subjectivity is due to inclusion of more general aspects of Anatomy and exclusion of specific deeper relevant Anatomy. Realizing this problem the present study was designed to formulate some principles for selecting course contents for the Anatomy portion of MD Internal Medicine course.
\end{abstract}

Study Design: This was a descriptive study.

Place \& Period of study: Center for Medical Education, Dhaka from July 2007-June 2008.

Method: It was based on analyses of opinion of students and teachers through focus group discussion involving teachers of Internal Medicine and Anatomy. These people were chosen through two stage random sampling within clusters. Two Focus group discussions were used to get feedback on the importance of various anatomical topics that should be included as course content. Of a total of 18 teachers response in focus group discussion. In FGD 83\% response was received from the teachers in Anatomy and $66 \%$ on teachers in Medicine.

Result: Opinion derived from the FGD indicate that for the selection of the course content following concluding remarks should be made:

- Cardiovascular anatomy, respiratory anatomy and anatomy of the nervous system should be considered important for the Internal Medicine.

- For knowing the anatomical landmarks all of the surface anatomy should receive attention for Medicine.

- Functional implication and effect of obliteration of arterial supply, lymphatic drainage and nerve supply receives importance.

- Sectional and radiological anatomy is considered important for the course for interpretation of X-ray, CT scan and MRI.

- Anatomical variation should be considered important as well as congenital anomalies of cardiovascular and genitourinary system.

- Knowledge of the structure of the mucous membrane is important for clinical correlation of the biopsy reports.

- Basic genetics, cell biology should be important but kept in mind that repetition should be avoided in others subjects as in Biochemistry and Physiology.

Key words: Anatomy, Course content, MD Internal medicine.

1. Associate Professor of Anatomy, BSMMU, Dhaka

2. Assistant Professor of Cardiology, DMCH, Dhaka

Correspondence: Dr. Laila Anjuman Banu 


\section{Introduction}

In our country, different types of course in different postgraduate clinical disciplines are being run under various universities with an aim to produce specialist clinicians and teachers for medical and allied disciplines. Postgraduate Degree-awarding Institute of Bangladesh are Bangabandhu Sheikh Mujib Medical University (BSMMU) which was known as the Institute of Postgraduate Medicine \& Research (IPGMR) before 1998, Bangladesh college of physician and surgeons (BCPS), Dhaka University, Chittagong University, Rajshahi University, Shahjalal University of Science \& Technology. BSMMU and old eight government medical colleges have been running different types of postgraduate courses for different clinical disciplines. Doctor of Medicine (MD) and Master of Surgery (MS) courses consist of three parts: Part-I, Part-II and Final Part. Duration of these courses is three academic years. In Part-I, students study the basic medical subjects for six months. Anatomy is included as one of the subjects in the first six months known as of Part-I of MD and MS courses of different postgraduate clinical disciplines.

But the problem is that in our postgraduate course much subjectivity is present in every aspects of curriculum. Actually, first need is to formulate objective what students should learn for a postgraduate course in terms of knowledge, skills and attitude. To produce a clinicians or surgeons with appropriate anatomical knowledge proper customized (relevant) course content regarding Anatomy part of all postgraduate disciplines is necessary. In the curriculum, there will be clear instruction that the Anatomy learning should be different in Medicine-biased (MD) and Surgerybiased (MS) courses. Moreover, there will be guidelines about in which aspects postgraduate learning of Anatomy should be different from undergraduate Anatomy (Wright V, 1975). The new 2202 curriculum for undergraduate Anatomy reveals that some topics in it like osteology have been emphasized possibly more than needed. Again, some topics are inadequate like clinical aspects of Anatomy. Subjectivity is also present in the assessment system of the Anatomy. Structuring of the assessment system is important in context of international standard (Jason H, 1974; Paul VK et al1 995). The learning process is also different in different medical colleges of our country. This creates variation of standard and ununiform knowledge of Anatomy among medical graduates. This variation might be the reasons to the varied background of the students coming to the postgraduate courses. Sometimes, they are inadequately prepared for the postgraduate knowledge.

In the Department of Anatomy of BSMMU, a guideline is provided to the students regarding the course content of Anatomy-portion of different postgraduate clinical courses, but that is a very preliminary one and does not fulfill the need of the courses in the light of knowledge of educational sciences (Gall MD, 1981). BCPS also provides course content for the fellowship in some disciplines, which helps to get an idea about the possible Anatomical topics that should provide guideline to prepare the curriculum for Internal Medicine.

The other medical colleges also started postgraduate courses in rapid succession with few guideline and examination format.

For uniform standard of postgraduate medical education in different universities this study may contribute to develop some principles that can guide course planner to develop uniform curriculum for the Anatomy part of the MD Internal medicine course. In addition, the selection of particular and specified need of the Anatomy part of the course content help an Internist in their future clinical context.

The present study was designed to identify the real problems in course contents for the Anatomy-portion of the Internal Medicine course and to find out some solution on the basis of the identified problem.

\section{Methodology}

The present study was a descriptive cross sectional study.

The teachers acting as Professor and Associate Professor were selected for an FGD. Teachers of Medicine and Anatomy posted in Dhaka (BSMMU, DMC, and SSMC) at the time of the study, as Professors, Associate Professors were selected by random method. A total of 24 teachers were selected for FGD. 


\section{Selecting teachers as participants (discussants) in the FGD.}

The names of the teachers in Anatomy and Internal Medicine who were working at any institution of the country at the time of the study as Professors, Associate Professors were collected from the souvenir of the latest conference of the Anatomical Society of Bangladesh and Association of Physicians of Bangladesh. From the list the names of the teachers who were available in Dhaka on the tentative day of discussion, were selected and their names were arranged in an alphabetical order. Then, they were contacted through telephone serially to take their consent about the participation in the focus group discussion. In this way, twelve teachers of Anatomy and twelve teachers of Internal Medicine were selected. They were invited through a letter. The agenda of the FGD and some supporting papers were also sent to their address.

\section{Supporting papers sent to the teachers approached for the FGD:}

- List of issues to be discussed

- Course content of the MD Internal Medicine course at IPGMR, Dhaka University, Shajalal University, Sylhet, BSMMU (Unofficial) University.

- Content pages of Medicine books.

Agenda of discussion:

- Objectives of the anatomy part of MD Internal Medicine course

- Course content of Anatomy part of MD Internal Medicine course of different Universities of Bangladesh

- Coverage of the course contents

- Distribution of the course contents

- Miscellaneous.

\section{Running of the focus group discussion}

On the day of the focus group discussion, the proceedings started with a welcome address from Prof Syeda Afroza, the supervisor of the present researcher. Then the present researcher introduced the agenda with a power point presentation. Then the discussants started commenting on the different agenda and continued for about two and a half hours.

The discussion was recorded in an audio cassette recorder after getting verbal consent from the discussants. The audio taped discussions were transcribed and analyzed by the researcher for getting the main points (themes), the details and the actual flavour.

\section{Data Processing and analysis}

The data gathered from the focus group discussion were analysed qualitatively, looking for the main 'themes' were emerging from the discussion on different agenda.

\section{Results}

In the focus group discussion several predetermined "Agenda" (topics) guided discussants. From the analysis of the transaction of the discussion, several issues (themes) emerged regarding different agenda. The following is an elaboration of the themes. Because of the close association, the themes from a number of agenda are grouped together.

Feedback regarding the course objectives and course contents:

\section{Theme-a :}

Objectives and course contents have to be reached to the students

Anatomist: The main goal is to become a clinician not an anatomist or a cell biologist

All of the teachers of Anatomy and Medicine opined that the Anatomy-portion should be clinically related to their discipline.

Anatomist: Most of the teachers said that the integration of Anatomy with its clinical application is equally important.

Internist: The students of Internal Medicine should have concept of Anatomy which will help them in clinical setting to correlate the disease with organ system rather than memorization.

Theme-b Duration of time as fixed by the university ( 6 months) and the course content have to be considered in order to complete the course.

Theme-c Course content for anatomy should not be minimized for Medicine

Most of the teachers said that course content should not be selective for MD Internal Medicine course and every aspect of Anatomy is needed. 
Anatomist: "the detailed relations of the structures may be minimized. Every system so far is important but I do not go for the relation of liver."

Another teacher suggested "just mere identification of structures and bone is not important but functional aspect of anatomy is essential".

Internist: One of the teacher expressed opinion strongly in favour of reflection and said

"No scope to curtail the content for Internal Medicine. Only the gross is not acceptable. We have learned the things from Grays even with the foot note but now the Clinical Anatomy of Snail is acceptable."

Another teacher told, "In terms of content it will be more regional like cardiology and nephrology but in Internal Medicine it will be more detail and elaborative."

One of the teachers opposed and told "not to prepare a list of contents but select taxonomy of specific educational objectives. Anatomical knowledge helps to understand that $3^{\text {rd }}$ cranial nerve lesion causes diplopia. Now we think to prepare a post-graduate curriculum, even now we run in a same circle like a repair workshop, we must go ahead".

Feedback regarding the different variables

Surface anatomy;

Theme-d Students have to know the anatomical landmarks.

All of the teachers of Anatomy and Medicine agreed that for Medicine surface anatomy is very important.

One of the internist argued "I am sure if I asked our MBBS doctors to palpate accessory nerve in a Leprosy patient, they are not able to do that. Our doctors do not know about the structures palpable under the skin. We must know all the subcutaneous palpable structures. If you asked trochenteric bursitis maximum graduates do not know where greater trochenter lies, they search for the trochenter anteriorly."

Another teacher told "all content of surface anatomy is acceptable."

Modes and functional implication and effect of severing of arterial supply

Theme-e Not all the name and branches of large artery is needed for them that are for the surgeons
One of the internist said that portal circulation and the porto systemic anastomoses is essential to know as it has clinical implication

Detailed mode of nerve supply/functional implication of nerve supply

Theme-f Medicine people definitely need the relationship with the central nervous system for conceptual understanding

One of the teachers argued" for understanding the transmission of pain one must go for the nervous system."

Mode of lymphatic drainage and clinical implication of lymphatic drainage

Theme-g Knowledge of the lymphatic drainage is needed when a clinician think of metastases.

All the teachers agreed that all regional lymph nodes and their area of drainage with palpation of enlarged lymph nodes should have anatomical basis.

Gross anatomical relation

Theme-h Gross Anatomy part may be reduced for Medicine.

One of the internist argued that not the details of surface, borders and the relation are important for them.

Radiological anatomy and sectional anatomy

Theme-i very much essential as CT, MRI and contrast images now are advancing

\section{One Anatomist strongly opposed}

I think basic idea of Radiological Anatomy is enough.

One of the internist said that very important, to know about extension of an organ like liver, seminal vesicle, location of an area like ischiorectal fossa.

\section{Light microscopic and ultramicroscopical aspects:}

Theme- $\mathbf{j}$ Knowledge of the structure of mucous membrane is likely to be included.

One of the teachers of Medicine

I do not except that they know all histology. We face all the biopsies of the body if you write all then it will be a hazardous. So, first we identify our need. Some histology is needed to know intrahepatic 
cholestasis. The canaliculi that are situated in between two hepatocyte that should be needed to understand in case of liver distortion.

Another teachr of Medicine told that very important for Medicine. Patient comes with erythema nodosum. The disease node sent to a pathologist. Clinical correlation with the report is needed. Internist correlates the report with their basic knowledge. If they do not know the histology of the skin how can then we correlate. So histology of all the organs is essential.

Another teacher told Ulcerative collitis will be diagnosed by observing the mucosal involvement upto the layer it involve. We differentiate ulcerative collitis from chron's disease from our histology knowledge.

Anatomist- In histolology we should include what histological changes occur in a disease. We have to use photograph and multimedia for teaching learning process to understand the ultrastructural aspects.

\section{Developmental anatomy and anomalies}

Theme-K The congenital anomalies if required that is for paediatrician they know the normal anatomical variations.

One of the teachers of Medicine

"If one does not know the congenital anomalies how he go ahead to diagnose diseases".

Cardiovascular embryology is very important. Anatomy of genitourinary system is important also as relevant to medicine.

Another teacher of Medicine

Anatomical variation should be highlighted as for example variation of tongue (geographical tongue) and developmental error of tongue.

One of the teachers of Anatomy

They know the General embryology also.

Anatomy of the physiological process and functional anatomy

Theme-I Anatomy of physiological process should have due importance

Anatomist- At this moment if we include these topics by pressure the basic or core knowledge may be neglected
Internist- If we include anatomy of kidney then why we neglect the anatomy of mechanism of glomerular filtration. These things are matter of approach and inclusion of these physiological process during teaching helps better understanding of anatomy.

Anatomy of clinical disorders and clinical procedures

Theme-m-Clinicians must know the anatomical basis of clinical disorders and procedures

A teacher of Medicine- I think some of the anatomy should be taught in clinical setting.

The knowledge of anatomy will be sound if anatomy should be taught in an integrated way. These topic is very much important for us.

\section{Cell biology and basic genetics-}

Theme-n-Every post graduate doctors should have idea about basic genetics and cell biology

Anatomist- I think general idea about cell biology is enough for clinicians. Changes that occur for a disease at cellular level they understand it by self learning process.

Internist- We have to know the genetic processes but as there is time constrain so repetition in biochemistry, physiology and pathology must be cautiously avoided.

\section{Discussion}

It is understood from the FGD that it is probably more important to consider the approach towards course content much more carefully. However, this must not be confused with any notion that anatomy part of the Medicine should be focusing only on very narrow regions.

The teachers in FGD recommend it how to deal the body or an anatomical issue of a particular organ or part of the body or an anatomical topic from the viewpoint of Medicine from just knowing that it is included in the course content. Even if a detailed list of parts, organs and topics are available to the teachers, examiners and students, each of them may differ from another in justifying different ways of dealing with those parts, organs and topics. The students of Internal Medicine should have concept of Anatomy which will help them to clinical setting 
so there should develop a concept rather than memorize. Some anatomy of clinical procedures like drainage of pleural fluid, anatomy of palpation of lymph nodes and anatomy of mechanism of development of portal hypertension are some examples. It should be much useful if the clinical procedures and clinical disorders in one hands and anatomy in the other could be correlated in the course content.

Scott (1994) cited several authors to justify the idea that "while medical students are highly motivated towards obtaining their license to practice, they understandingly develop lack of motivation to learn seeming irrelevant material such as that usually offered in the early years in most schools". On the other hand, clinical correlation of basic science subjects has been found (through problem-based learning curriculum) to make more positive impact on the student's attitude towards these subjects at preclinical levels as compared to conventional lecture-based curriculum (Kaufman and Mann 1997). The postgraduate students are supposed to be altogether keener to have their learning directly related to their clinical ambition. Thus, the Anatomyportion of the postgraduate course must address this relationship much more vigorously.

It is expected that postgraduate students would be much keener as well as able to develop understandings of various anatomical topics in the context of clinical problems than the undergraduates. De Monchy (1992) realized that attitudes consist of predispositions to respond in a certain maneuver. Appreciating this notion, Kaufman and Mann (1997) expressed their understanding that "if students are to apply the basic sciences to their clinical experience they must perceive these as relevant" (Jason 1974; Nossal 1976 and AAMC 1991, both cited by Kaufman and Mann 1997)

Careful analysis of the data of the present study indicates that while there are some aspects of Anatomy that are relevant to almost any medical postgraduate course, a much more regional approach is required for the Medicine. The former group includes aspects like Cell Biology, Genetics and General Histology, while the latter would include specific portions of Topographic Anatomy, Systemic
Embryology, Anatomy of Imaging (Radiographic Anatomy), Surface Anatomy, Clinical Anatomy, Systemic Histology etc. This approach however, calls not only for reducing the range of topics covered in a Internal Medicine course, but also for focusing on specifically relevant topics with a greater depth of focus. "It must be recognized from the beginning of a study that an anatomical structure (organ, blood vessel, nerve, muscle, bone, or other) is not always confined to only one anatomical region. Therefore it may be necessary to explore several regions to appreciate morphologically a structure as a whole" (Vidicì and Suarez 1984).

However, the topographic anatomy and surface anatomy is very much required for Medicine but sometime in reality general anatomy is asked much more than relevant. It happens with some examiners that because specimens is made available at the oral exam table, an examiner may be asked to identify various parts of the specimens and about the anatomical position but may not be asked a single question on the concept of sectional anatomy as is important for an would-be internist. This happens because of the fact that the objectives and course content of a course are not properly clarified in any document of a course.

\section{References:}

1. Curriculum for postgraduate course, 2005. BCPS, Bangladesh.

2. Curriculum for postgraduate medical students of Bangladesh, 2002.

3. Curriculum of Anatomy course for undergraduate medical students of Bangladesh, 2002.

4. DE Monchy C. Professional attitudes of doctors and medical teachers. Medical teacher, 1992; 14: 327-31.

5. Institute of Postgraduate Medicine and Research. Manual. Dhaka: The Institute; 1990.

6. Jason $\mathrm{H}$. Evaluation of basic science learning: implications of and for the GAP report. Journal of Medical Education, 1974; 49: 1003-4.

7. Kasper DL, Braunwald E, Fauci AS, Hauser S, Longo D. Jameson JL, ed. 2004. Harrison's 
Principles of Internal Medicine. $16^{\text {th }}$ edition. UK: McGraw-Hill.

8. Kasper, Dennis L, Braunwald, Eugene, Fauci, Anthony, et al., ed. 2005. Harrison's Principles of Internal Medicine. $16^{\text {th }}$ ed. UK: McGraw Hill.

9. Kelly DE, Wood RL, Enders AC, ed. Bailey's textbook of microscopic anatomy. $18^{\text {th }}$ ed. Baltimore: Williams \& Wilkins. 1985

10. Kumar PJ, Clark ML. Kumar and Clark clinical Medicine. $5^{\text {th }}$ ed. UK: WB Saunders. 2002.

11. Paul VK, Shahni P, Mittal S, Kharbanda OP, Adkoli BV, Verma $\mathrm{K}$ et al. Assessment in medical education, trends and tools. New Delhi: K.L. Wig Centre for Medical education and technology. 1995.

12. Scott TM. A case-based anatomy course. Medical Education, 1994; 28: 68-73.

13. Vidic B. Suarez RF, 1984. Photographic atlas of the human body. St Louis: The C.V. Mosby Company.

14. Wright V, Hopkins R, Burton KE, 1979. What shall we teach undergraduates? British Medical Journal, 1, 805-7. 